\title{
Metabolomics and microbiome profiling as biomarkers in obstructive sleep apnoea: a comprehensive review
}

\author{
Xiaoman Zhang ${ }^{1,2,3,4}$, Shengming Wang ${ }^{1,2,3,4}$, Huajun $\mathrm{Xu}^{1,2,3}$, Hongliang $\mathrm{Yi}^{1,2,3}$, Jian Guan ${ }^{1,2,3}$ and \\ Shankai Yin ${ }^{1,2,3}$
}

${ }^{1}$ Dept of Otolaryngology Head and Neck Surgery \& Center of Sleep Medicine, Shanghai Jiao Tong University Affiliated Sixth People's Hospital, Shanghai, China. ${ }^{2}$ Shanghai Key Laboratory of Sleep Disordered Breathing, Shanghai, China. ${ }^{3}$ Otolaryngological Institute of Shanghai Jiao Tong University, Shanghai, China. ${ }^{4}$ Both authors contributed equally.

Corresponding author: Huajun Xu (sunnydayxu2010@163.com)

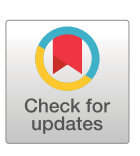

This version is distributed under the terms of the Creative Commons Attribution Non-Commercial Licence 4.0. For commercial reproduction rights and permissions contact permissions@ersnet.org

Received: 8 July 2020 Accepted: 3 Dec 2020

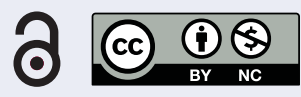

Shareable abstract (@ERSpublications)

Unique alterations in metabolism and the microbiome play an integral role in the pathophysiology of OSA and OSA-induced cardiovascular complications https://bit.ly/3mW2rD5

Cite this article as: Zhang $\mathrm{X}$, Wang $\mathrm{S}, \mathrm{Xu} \mathrm{H}$, et al. Metabolomics and microbiome profiling as biomarkers in obstructive sleep apnoea: a comprehensive review. Eur Respir Rev 2021; 30: 200220 [DOI: 10.1183/16000617.0220-2020].

\section{Abstract}

Introduction Obstructive sleep apnoea (OSA) is a common sleep disorder with a high social and economic burden. Thus, early prediction and diagnosis of OSA are important. Changes in metabolism and the microbiome may serve as biomarkers for OSA. Herein, we review the literature on the metabolomic and microbiome changes associated with OSA, and identify the metabolites and microorganisms involved. Methods We searched the PUBMED and EMBASE electronic databases using the following terms: "obstructive sleep apnea”, “OSA”, “sleep disordered breathing”, “SDB”, “intermittent hypoxia”, "sleep fragmentation", and either "metabolomics” or "microbiome”. In total, 273 papers were identified, of which 28 were included in our study.

Results Changes in the levels of certain metabolites related to fatty acid, carbohydrate and amino acid metabolism were associated with the incidence of OSA. The diversity and abundance of microflora, particularly Firmicutes and Bacteroidetes, were altered in humans and rodents with OSA.

Conclusions Certain changes in metabolism and the microbiota play an integral role in the pathophysiology of OSA and OSA-induced cardiovascular complications. Metabolomic and microbiome biomarkers shed light on the pathogenesis of OSA, and facilitate early diagnosis and treatment.

\section{Introduction}

Obstructive sleep apnoea (OSA) is the most common form of sleep disordered breathing and is caused by collapse and obstruction of the upper airway during sleep. It has been estimated that 425 million adults (aged 30-69 years) worldwide have moderate to severe OSA [1]. Patients with OSA are more likely to snore, and show sleep structure disorder and daytime sleepiness, which decrease sleep quality and reduce performance at work. OSA has been associated with an increased risk of cardiovascular, metabolic and cognitive disorders [2-4]. Some evidence indicates that OSA is associated with patients with impaired lipid metabolism; in particular, hyper-low-density lipoprotein cholesterol levels are independently correlated with OSA [5, 6]. In summary, OSA has a significant impact on individual health and imposes a large burden on society.

The gold standard for diagnosing OSA is overnight polysomnography (PSG) [7]. However, PSG is expensive and time consuming, which hinders its utility for the prevention, early diagnosis and treatment of OSA. Thus, identifying biomarkers for OSA has been the focus of research for more than a decade. The development of metabolomics and metagenomics technologies has drawn more attention to OSA. Metabolomics involves qualitative and quantitative analysis of small metabolites $(<1500 \mathrm{Da})$ [8], and provides metabolic information. Metabolomics directly reflects the activity of metabolic pathways occurring at a particular moment, and can amplify small changes controlled at the level of the genome and/ 
or proteome [9]. Metabolomics studies can be divided into targeted and nontargeted types. In targeted metabolomics, predetermined components of one or several biofluids are analysed, whereas nontargeted metabolomics analyses all metabolic components in a specific biological sample, which is usually used to find new biomarkers [10]. There are three platforms for nontargeted metabolomics: nuclear magnetic resonance (NMR) imaging; gas chromatography-mass spectrometry; and liquid chromatography-mass spectrometry. The role of the microbiome in the development of disease should also not be underestimated. The activities of the microbiota are readily affected by environmental stimuli and have been linked to host immunity and metabolism [11]. Progress in the microbiome and metabolomics studies could reveal the pathological processes underlying OSA and thus inform diagnostic methods. In this study, we review studies on the metabolism and microflora of OSA in humans and rodents.

\section{Methods}

The PUBMED and EMBASE electronic databases were searched for relevant studies using the keywords “obstructive sleep apnea”, “OSA”, “sleep disordered breath”, “SDB”, “intermittent hypoxia” and “sleep fragmentation" together with "metabolomics”. This search identified 115 articles. After a selection process, 10 articles were finally included.

Similarly, the same keywords “obstructive sleep apnea”, “OSA”, “sleep disordered breath”, "SDB”, "intermittent hypoxia” and "sleep fragmentation" together with "microbiome” were used for searching and a total of 162 papers were identified. After selection, 18 articles were finally adopted from this search.

\section{Results}

The search identified 273 articles which was reduced to 228 after removing duplicates. After reviewing the titles and abstracts, a further 150 studies that did not address the topic of our review were excluded. The full texts of the remaining 78 studies were screened, and the studies that did not meet the search criteria were excluded. The exclusion criteria were: 1) any nonoriginal research articles (e.g. evaluation articles and conference reports); 2) any review; 3) ongoing research; and 4) research articles that used a repeated study population. The final number of original articles included in this review was 28 . A flowchart of the study selection process is presented in figure 1.

\section{OSA and metabolomic biomarkers}

\section{Animal models}

Intermittent hypoxia (IH) plays a pivotal role in the pathophysiology of OSA. In fact, most rodent studies have used $\mathrm{IH}$ as a model of OSA. CoNOTTE et al. [12] used NMR imaging for urinary metabolomic profiling in a mouse model of IH. They found increased levels of lactate and trans-aconitate, and decreased levels of pyruvate, citrate, succinate and acetoacetate, indicating that the energy metabolic pathways of $\mathrm{IH}$ mice were predominately anaerobic metabolism. Oxidative stress is another pathological feature of OSA [13] and has been confirmed in $\mathrm{IH}$ mice (reflected in increased levels of oxidation products, such as allantoin and trimethylamine oxide (TMAO)) [12]. ConotTe et al. [12] suggested that hypoxia-induced oxidative stress might promote changes in metabolism in OSA.

a)

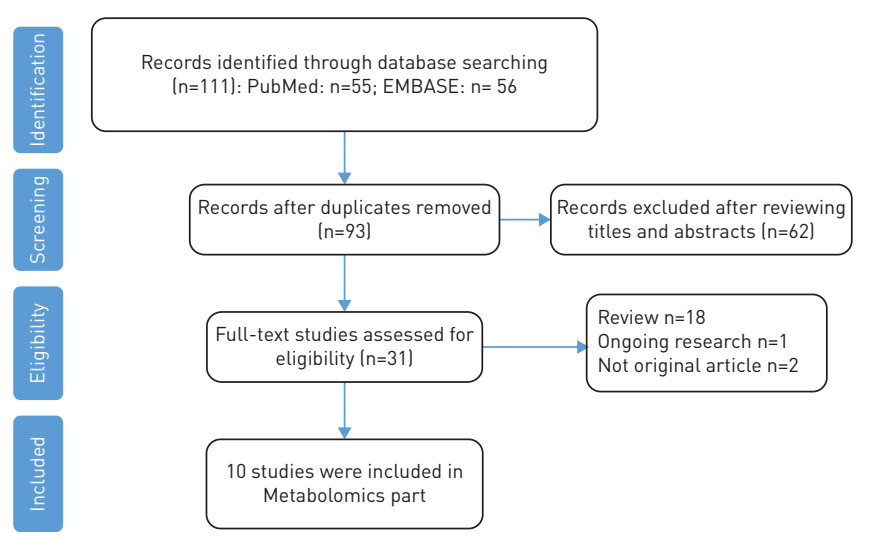

b)

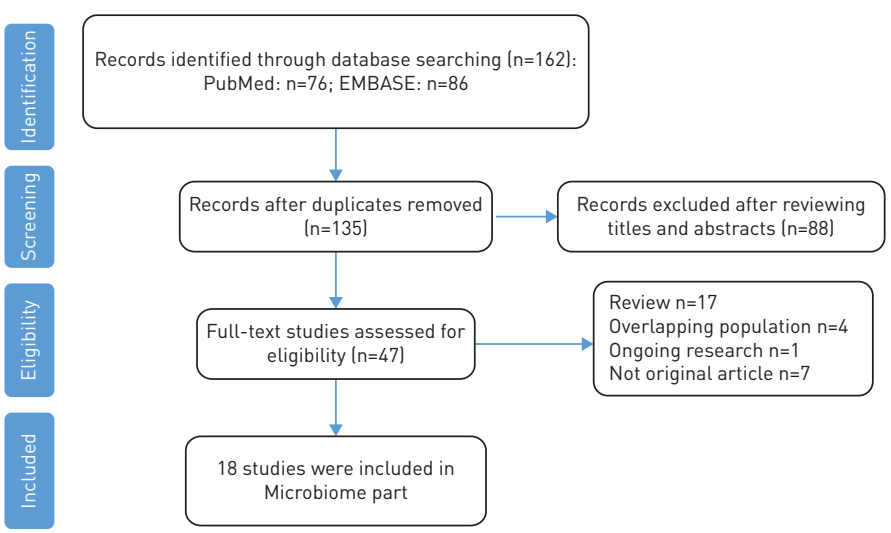

FIGURE 1 Flowchart of selecting literature in a) metabolomics and b) microbiome. 
Sleep fragmentation (i.e. frequent brief awakenings), is another key feature of OSA. Yoon et al. [14] explored hippocampal metabolite profiles in rats with sleep fragmentation to understand the mechanism of the associated neurocognitive dysfunction. Metabolites in the hippocampus related to excitatory neurotransmitters, such as glutamate and aspartate, were present in significantly smaller quantities in the chronic sleep fragmentation group, possibly as a protective mechanism against the excitatory toxicity associated with frequent awakening. Precursors of acetylcholine (methionine and choline), an important neurotransmitter in brain function, were also below normal levels in the chronic sleep fragmentation rats. These findings may explain why sleep fragmentation affects memory and learning ability.

Human studies

Serum/plasma, urine, saliva and faecal extract can be analysed in human metabolomics studies. Analysis of different biofluids is useful for understanding different metabolic changes, as summarised in the following sections.

Urine

An NMR imaging study by ZĄBEK et al. [15] revealed that 10 urinary metabolites were better able to distinguish between OSA and COPD than analysis of two or three different biofluids, although these results have been questioned in terms of specificity [16]. Also, data on smoking status, disease severity and COPD as a comorbidity are needed to allow comparison among OSA studies.

XU et al. [17] compared metabolite levels among simple snorers, OSA patients and healthy subjects. A total of 21 and 31 metabolites in simple snorers and OSA subjects showed differences, respectively, from normal controls. Most fatty acids and fatty acid-related compounds (e.g. 2,4-dihydroxybutyric acid, 3,4-dihydrxoybutyric acid, pentanoic acid and glyceraldehyde), which are associated with abnormal lipolysis in cases of IH, were elevated in OSA subjects compared with controls. Glycolytic intermediates associated with ATP production, and branch chain amino acids (BCAAs) associated with mitochondrial dysfunction, were also elevated in OSA subjects compared with controls. BCAAs, such as leucine, isoleucine and valine are important biomarkers of insulin resistance, and accumulation is associated with the risk of type 2 diabetes mellitus (T2DM) [18]. Hence, metabolic profiles overlap between chronic inflammatory and metabolic diseases. Intestinal flora-related metabolites, such as TMAO and glycochenodeoxycholate-3-sulfate, show significantly increased expression in subjects with OSA [17]. Individuals with OSA can be distinguished from healthy individuals based on the expression levels of six metabolites (4-hydroxypentenoic acid, arabinose, glycochenodeoxycholate-3-sulfate, isoleucine, serine and xanthine) with $75 \%$ sensitivity and $78 \%$ specificity [17].

Meta-analyses have shown that the risk of adverse cardiovascular effects increases in those with moderate to severe OSA [19, 20]. Stroke and coronary artery disease have a dose-response relationship with OSA severity [21, 22]. Although the mechanism of the association between OSA and cardiovascular disease is not fully understood, neurohormonal dysregulation, metabolic abnormalities, and inflammation may be responsible for cardiovascular events in patients with OSA [23]. There is a complex but strong association between OSA and cardiovascular disease and certain biomarkers of cardiovascular disease could assist in the clinical diagnosis and prediction of OSA-induced cardiovascular diseases, especially through cell and rodent experiments. Targeted metabolomics identified three urinary metabolites, namely long-chain acylcarnitine (C14:1) and the biogenic amines of symmetric dimethylarginine (SDMA) and sphingomyelin (C18:1), which could be used as predictive biomarkers of OSA [24]. Changes in acylcarnitine levels indicate disordered lipid metabolism and an imbalance of $\beta$-oxidation of fatty acids in OSA. Fluctuations in SDMA, associated with nitric oxide metabolism, and in sphingomyelin, associated with lipoprotein formation, drove high risk of OSA-related heart disease.

Xu et al. [25] reported that 57 metabolites in paediatric OSA patients were significantly different from those in control patients. Of the metabolites, 52 were associated with amino acid, carbohydrate, microbial, vitamin, nucleic acid, fatty acid, butanoate, bilirubin metabolism or the ornithine cycle. Paediatric OSA subjects presented with more metabolites associated with abnormal carbohydrate and amino acid metabolism than adult subjects with OSA, possibly due to different pathogenic mechanisms; adult OSA seems to be more related to obesity, whereas paediatric OSA correlates with adenoid and tonsil hypertrophy [26, 27]. This could explain why abnormal lipid metabolism is more prevalent in adult than paediatric OSA patients.

Serum or plasma

Two studies [28, 29] used blood-derived biofluids to characterise the metabolomic profiles of patients with OSA. The first of these studies [28] reported that 14 significant metabolites were altered in subjects with 
more versus less severe OSA, including porphyrins, glycerophospholipids (GPLs), fatty acids, eicosanoids, amino acids, and peptides. Porphyrins are endogenous pigments that protect against oxidative stress. Among the GPLs, lysophospholipids and O-alkyl GPLs are thought to influence phospholipase A2 family members, which could affect the production of inflammatory mediators and platelet aggregation [28]. Thus, the decrease in GPL expression seen in patients with severe OSA may increase the risk of cardiovascular events by promoting inflammation and platelet aggregation, in accordance with the relationship between the severity of OSA and cardiovascular events. The decrease in porphyrin and GPL expression in severe OSA patients indicates that oxidative processes induce inflammation, which could be a causal or contributing factor in severe OSA [28]. An increase in piperic acid, which reflects the catabolism of lysine by intestinal flora, was seen in severe patients [28]. Although the study was not adjusted for sex or smoking, and OSA was not confirmed by PSG, it clearly distinguished between mild and severe patients through nontargeted metabolomics.

LEBKUCHEN et al. [29] found that the expression of four metabolites (deoxy sugar; 2,6-diphenyl-1,7dihydrodipyrrolo[2,3-b:3',2'-e] pyridine; 9-hexadecenoic acid; and arachidonic acid) related to glucose and inflammation increased markedly in patients with OSA, whereas two metabolites (5,5'-biphthalide and L-glutamine) showed decreased levels. That study recommended that these biomarkers be used to predict the risk of cardiovascular complications and metabolic disorders in patients with OSA. The results of OSA metabolomic studies in human and rodents are summarised in table 1, and the metabolic changes associated with OSA are summarised in figure 2a.

\section{Summary of metabolomics studies}

Disrupted amino acid, carbohydrate, fatty acid, xanthine and bilirubin metabolism has been described in OSA patients and rodent models [12, 17, 24, 25, 28, 29]. Changes in glycolytic intermediates correspond with altered energy production in cases of IH [12]. Porphyrin and xanthine-related metabolites indicate a role of oxidative stress in the pathology of OSA [12, 28]. Metabolites associated with lipid metabolism may be especially important, and an increase in carnitine has been confirmed in human OSA studies [17, 24, 28]. These results indicate that changes in the intermediate products of aerobic and anaerobic metabolism are related to the hypoxia seen in OSA. Allantoin, an end product of xanthine metabolism and reactive oxygen species (ROS) marker, is produced through a uricase-catalysed reaction or a simple redox process [30]. Allantoin is only present in the urine when ROS are expressed and reflects the oxidative stress status of patients with OSA, making it a suitable biomarker for the disorder. Dietary choline is decomposed by intestinal flora into trimethylamine, which is catalysed by flavin-containing monooxygenase 3 in the liver to produce TMAO [31]. TMAO is a modulator of cholesterol and sterol metabolism that contributes to foam-cell formation from macrophages, which directly play a direct role in atherosclerosis and cardiovascular disease [32]. Animal models of dietary choline and TMAO have confirmed the role of the latter in platelet aggregation and thrombosis [33]. In addition, TMAO may reduce adverse effects of oxidative stress, serving as an electron acceptor [34]. TMAO has the potential to predict the risk of OSA-induced cardiovascular disease, but the effects of TMAO in OSA patients are nonspecific. TMAO increases in diseases associated with a high risk of cardiovascular events, such as T2DM. Thus, it is not suitable as a biomarker of OSA, but could be used to predict the risk of cardiovascular events in OSA patients. Although metabolomics has proven ability to reflect the pathophysiological state at a given time, some limitations must be addressed. The reliability of the results described above is limited due to small sample sizes, cross-sectional designs, and a lack of adjustment for confounding variables.

\section{OSA and the microbiome}

\section{Animal models}

A complex microbial community exists in mammals, which is mainly controlled by obligate anaerobic bacteria (Firmicutes and Bacteroidetes). The dynamic balance between Firmicutes and Bacteroidetes is a defining feature of the human gut [35]. When animals are in a state of IH (characteristic of OSA), the arterial oxygen tension $\left(\mathrm{P}_{\mathrm{aO}_{2}}\right)$ in the intestinal lumen fluctuates and its average level drops. Significant changes in intestinal microorganism expression are seen in a hypoxic environment, mainly manifested as an increase in Prevotella and Desulfovibrio and a decrease in Bacteroides species [36]. The change in $P_{\mathrm{aO}_{2}}$ provides an ecological advantage for obligate anaerobic Gram-negative bacteria, which disrupt the structure of the intestinal microbial community. After 6 weeks of normoxic recovery, the abundance of Firmicutes increases, and that of Bacteroidetes decreases, compared with healthy controls, and circulating lipopolysaccharides (LPS) are highly correlated with the abundance of Desulfovibrio [37]. Thus, 6 weeks is insufficient to reverse flora disorders in OSA. Prevotella and Desulfovibrio play an important role in maintaining mucosa. Prevotella is involved in the degradation of mucin and Desulfovibrio prevents interference by sulfate during the degradation process [38]. Therefore, the increased abundance of 
TABLE 1 Obstructive sleep apnoea (OSA) and metabolomics (rodent and human studies)

\begin{tabular}{|c|c|c|c|c|c|}
\hline $\begin{array}{l}\text { First author } \\
\text { [ref.] }\end{array}$ & $\begin{array}{l}\text { Analytical } \\
\text { techniques }\end{array}$ & Sample & Participants & Complications & Main results \\
\hline Conotte [12] & NMR & Urine & $\begin{array}{l}\text { Male C57BL6J } \\
\text { mice }\end{array}$ & & $\begin{array}{l}\text { The energy metabolism pathway of mice } \\
\text { under IH predominately switched to } \\
\text { anaerobic metabolism } \\
\text { The level of oxidation products increased in } \\
\text { mice under IH }\end{array}$ \\
\hline Yoon [14] & LC/MS & Hippocampi & Male Wistar rats & & $\begin{array}{l}\text { Metabolites related to neurotransmitters, } \\
\text { such as glutamate and aspartate in the } \\
\text { hippocampus decreased significantly in } \\
\text { chronic SF groups } \\
\text { Precursors (methionine and choline) of } \\
\text { acetylcholine were shown to be below } \\
\text { normal levels in the SF model }\end{array}$ \\
\hline$Z_{\text {ĄEK }}[15]$ & NMR & $\begin{array}{l}\text { Urine and } \\
\text { serum }\end{array}$ & $\begin{array}{l}18 \text { COPD and } \\
28 \text { OSA }\end{array}$ & $\begin{array}{l}\text { Over half of the } \\
\text { participants have } \\
\text { cardiovascular disease }\end{array}$ & $\begin{array}{l}\text { Urine metabolites presented the highest } \\
\text { probability for identifying patients with } \\
\text { COPD } \\
\text { A combination of different biofluids detection } \\
\text { did not improve the diagnosis power }\end{array}$ \\
\hline $\mathrm{Xu}[17]$ & $\begin{array}{l}\text { UPLC-Q-TOF-MS/ } \\
\text { GC-TOF-MS }\end{array}$ & Urine & $\begin{array}{l}60 \text { OSA, } 30 \text { SS } \\
\text { and } 30 \text { controls } \\
\quad(\mathrm{AHI}>10)\end{array}$ & $\begin{array}{l}\text { Without medical history } \\
\text { of systemic disease }\end{array}$ & $\begin{array}{l}\text { Metabolites from fatty acid and phospholipid } \\
\text { metabolism expressed differentially in SS } \\
\text { and OSA } \\
\text { Dyslipidaemia caused by IH may be involved } \\
\text { in the development of OSA }\end{array}$ \\
\hline Сно [24] & MS & Urine & $\begin{array}{l}34 \text { male OSA and } \\
14 \text { controls } \\
(\mathrm{AHI}>8)\end{array}$ & $\begin{array}{l}\text { Without medical history } \\
\text { of DM, hyperlipidaemia, } \\
\text { and chronic } \\
\text { hypoxia-related diseases }\end{array}$ & $\begin{array}{l}\text { Three metabolites, long-chain acylcarnitine } \\
\text { (C14:1), biogenic amines of SDMA and } \\
\text { sphingomyelin (C18:1) were significantly } \\
\text { elevated in OSA male patients }\end{array}$ \\
\hline $\mathrm{Xu}[25]$ & $\begin{array}{l}\text { UPLC-Q-TOF-MS/ } \\
\text { GC-TOF-MS }\end{array}$ & Urine & $\begin{array}{c}30 \text { paediatric } \\
\text { OSA and } 30 \\
\text { controls (average } \\
\text { AHI 4.1) }\end{array}$ & $\begin{array}{l}\text { Without medical history } \\
\text { of systemic disease }\end{array}$ & $\begin{array}{l}52 \text { metabolites from nine pathway classes } \\
\text { (amino acid, carbohydrate, microbial, } \\
\text { vitamin, nucleic acid, fatty acid, butanoate, } \\
\text { bilirubin metabolism and ornithine cycle) } \\
\text { were identified in paediatric OSA }\end{array}$ \\
\hline FERRARINI [28] & LC-QTOF-MS & Plasma & $\begin{array}{l}15 \text { nonsevere } \\
\text { OSA }(\mathrm{AHI}<30) \\
\text { and } 18 \text { severe } \\
\text { OSA }(\mathrm{AHI}>30)\end{array}$ & $\begin{array}{l}\text { Without screening of } \\
\text { complications }\end{array}$ & $\begin{array}{l}14 \text { significant metabolites related to } \\
\text { inflammation and hypoxia in plasma } \\
\text { samples were identified to differentiate } \\
\text { mild OSA patients from severe patients }\end{array}$ \\
\hline LEBKuCHEN [29] & GC-MS/MS & Plasma & $\begin{array}{l}37 \text { OSA and } 16 \\
\text { controls } \\
(\mathrm{AHI} \geqslant 15)\end{array}$ & $\begin{array}{c}\text { Without medical history } \\
\text { of diabetes }\end{array}$ & $\begin{array}{l}\text { Glutamic acid, deoxy sugar, arachidonic acid, } \\
\text { glycerophosphoethanolamines, } \\
\text { sphingomyelin and lyso-phosphocholines } \\
\text { were related to OSA }\end{array}$ \\
\hline
\end{tabular}

NMR: nuclear magnetic resonance; LC: liquid chromatography; MS: mass spectrometry; UPLC-Q-TOF-MS: ultra-performance liquid chromatography coupled with quadrupole time-of-flight mass spectrometry; GC-TOF-MS: gas chromatography coupled with time-of-flight mass spectrometry; SS: simple snorers; IH: intermittent hypoxia; SF: sleep fragmentation; AHI: apnoea-hypopnoea index; DM: diabetes mellitus; SDMA: symmetric dimethylarginine; LC-QTOF-MS: liquid chromatography coupled with quadrupole time-of-flight mass spectrometry; GC-MS: gas chromatographymass spectrometry.

Prevotella and Desulfovibrio promotes changes in mucosal permeability, which may result in high blood levels of LPS.

Similar microbial changes are observed in sleep fragmentation models at the phylum level; these include increased abundance of species in the Ruminococcaceae family and decreased abundance of species in the Lactobacillaceae family [39, 40]. Ровоүко et al. [39] reported that 4 weeks of sleep fragmentation led to inflammation of the mesenteric adipose tissue in mice, suggesting that microbial translocation and invasion elicited a bacteria-derived inflammatory load. However, TRIPLETT et al. [40] reported that the abundance of intestinal bacteria was significantly changed by prolonged sleep fragmentation, but intestinal permeability and inflammation did not occur. There were differences in sleep fragmentation between these two studies, in terms of the frequency of awakening, which may affect the extent of pathology. In addition, these two studies used different animal interference periods (e.g. in the rat experiment, there was a safety time of $3 \mathrm{~h}$ 
a)

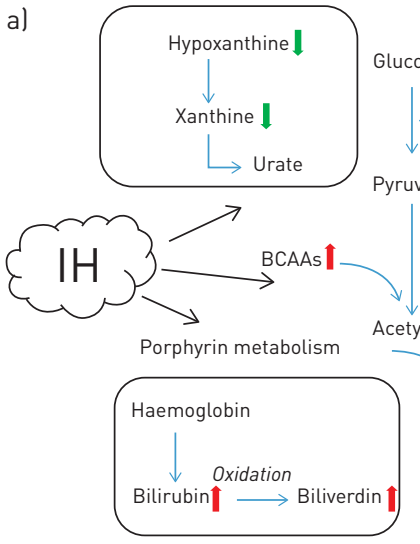

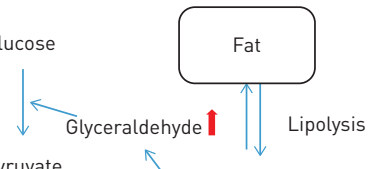
Glycerol + Free fatty acids and Lactate
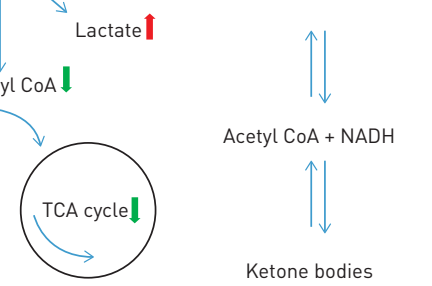
Acetyl $\mathrm{CoA}+\mathrm{NADH}$

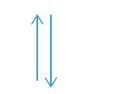

Ketone bodies b) Kingdom Phylum Class Order Family Genus

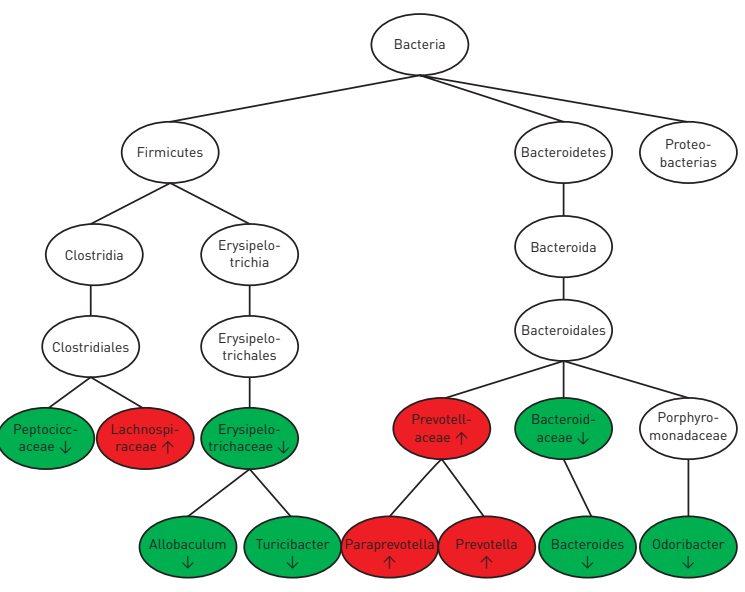

\section{c)}
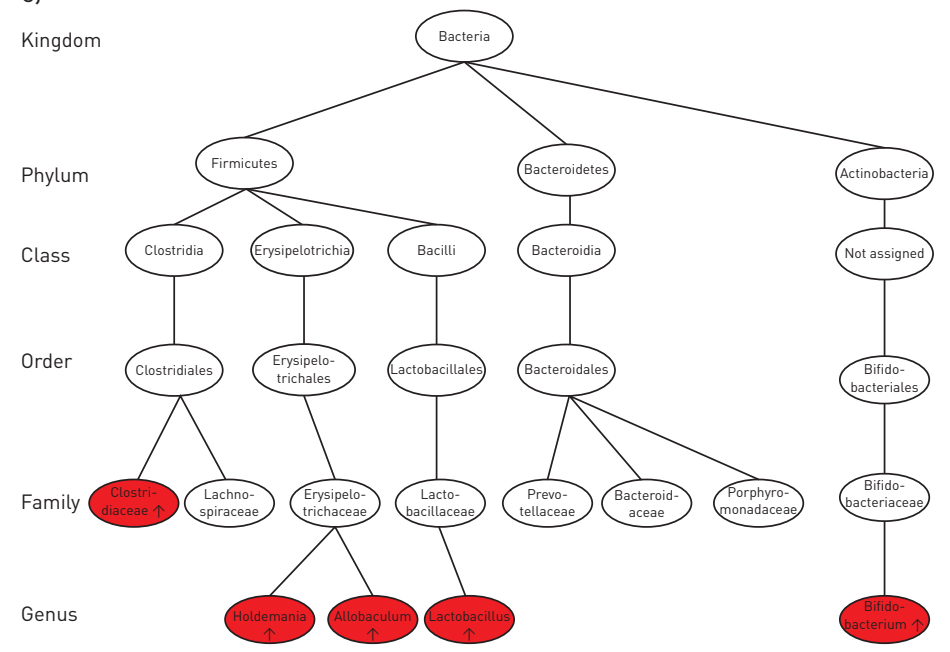

d)

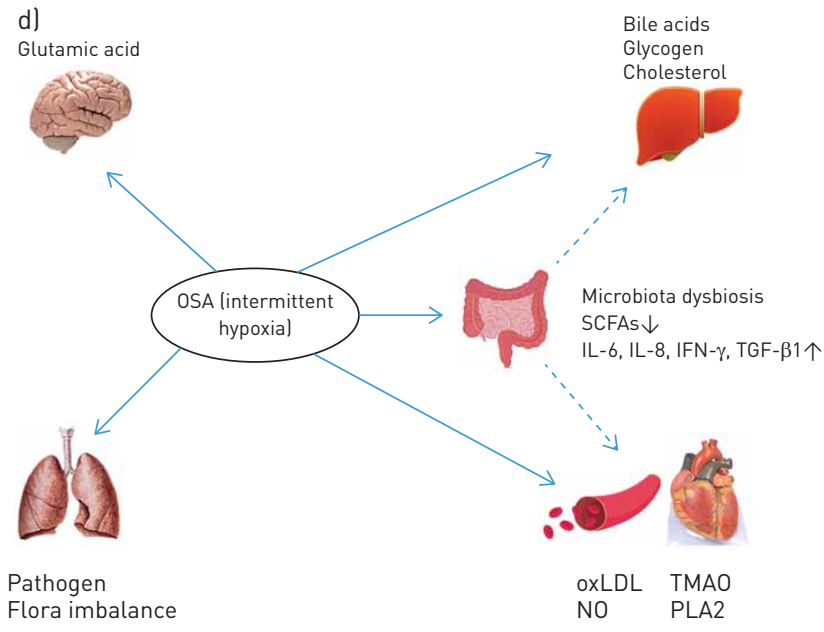

FIGURE 2 a) Summary of metabolic alterations in obstructive sleep apnoea (OSA). The red arrows represent an increased level, while the green arrows represent a decreased level. IH: intermittent hypoxia; BCAAs: branch chain amino acids; TCA: tricarboxylic acid; NADH: nicotinamide adenine dinucleotide. b) Alterations of gut microbiota in OSA rodent models. Red represents an increase in relative abundance, while green represents a decrease. c) Alterations of gut microbiota in OSA-induced hypertension models. Red represents an increase in relative abundance. d) Cardiovascular, hepatic, pulmonary and cerebral complications caused by OSA and influenced by microbiota dysbiosis. The dotted arrows refer to the unclear mechanisms and pathophysiological pathways. SCFA: short-chain fatty acids; IL: interleukin; TGF: transforming growth factor; oxLDL: oxidised low-density lipoprotein; TMAO: trimethylamine oxide; PLA2: phospholipase A2; NO: nitric oxide.

during sleep). There is evidence that the endogenous circadian rhythm is a key modulator of the gut microflora [41]. Thus, pathological manifestations may be related to a disturbance of the circadian rhythm, which affects the microbiota profile in animal models and increases the release of inflammatory factors.

OSA is also an independent risk factor for hypertension. Several epidemiological studies have reported a relationship between OSA severity, defined based on apnoea-hypopnoea index (AHI) and hypertension [42-44]. However, support for a causal relationship between OSA and hypertension comes from animal experiments; the relationship between OSA severity and the intestinal flora in patients with OSA-induced hypertension has not yet been explored. However, some biomarkers of hypertension could assist the diagnosis and prediction of OSA-induced hypertension, which would help clarify the underlying mechanisms in cell and rodent experiments. Many studies [45, 46] have confirmed that, over a short period, OSA alone is insufficient to cause hypertension, except in the presence of a high fat or high salt diet. Moreover, repeated awakenings did not lead to blood pressure elevations in the absence of hypoxia [47]. The combination of OSA and a high salt diet promotes hypertension by raising the level of TMAO in the blood and disrupting the regulation of inflammation [46]. Transplanting caecal contents from OSA-induced hypertensive rats into OSA rats on a normal diet increases blood pressure in the recipient animals [45]. Thus, dysbiosis is involved in OSA-induced 
hypertension, and dysbiosis and hypertension seems to be linked by bacterially produced short-chain fatty acids (SCFAs) (primarily acetic, propionic and butyric acids). SCFAs originate from microbial metabolism of dietary fibre in the intestine, where they exert effects on intestinal health and homeostasis by stabilising the intestinal epithelial barrier and regulating cytokine and antibody secretion [48]. Several gut microfloral analyses [45, 49, 50] have shown that bacteria associated with SCFA production decrease in OSA-induced hypertension models. SCFAs are involved in fatty acid synthesis and gluconeogenesis and can increase liver triglyceride levels, thus promoting intestinal energy metabolism and obesity [51]. However, elsewhere it was reported that SCFAs may also increase energy consumption, and the production of satiety hormones, thus preventing obesity [52]. SCFAs increase the number and suppressive function of colonic anti-inflammatory regulatory $\mathrm{T}$ (Treg) cells by acting on G protein-coupled receptor (GPR)-43 [53]. There is some evidence that SCFA-producing bacteria, such as Faecalibacterium, Oscillibacter and Howardella, are decreased in patients with OSA compared with controls, indicating that a decrease in the anti-inflammatory effect of SCFAs might promote the occurrence and progression of OSA [54]. In addition, SCFAs regulate blood pressure by activating Gpr-41 expressed in the smooth muscle cells of small resistance vessels [55]. Therefore, the decrease of SCFAs in patients with OSA may promote obesity, inhibiting the anti-inflammatory effect and worsening hypertension. Prebiotic and probiotic treatments have been applied to further verify the role of SCFAs in OSA-induced hypertension [49]. After Clostridium butyricum and Hylon probiotic treatments, the bacteria associated with SCFAs increase significantly in rats, and these treatments lessen the influence of decreasing acetate concentrations in the caecum by inhibiting interleukin- $1 \alpha$ and interleukin- 6 mRNA expression. Similarly, in an OSA model, gut dysbiosis was confirmed to be associated with the risk of cardiac consequences. The expression of Clostridiaceae and Coriobacteriaceae family members decreased significantly, while the expression of Lachnospiraceae family members increased, in OSA-induced models of hypertension compared with controls $[56,57]$. However, a high fat or high salt diet, was used to simulate the cardiovascular complications in these experiments, which also used transgenic rodents with high susceptibility to obesity. Accordingly, the results may have been confounded by dietary and genetic factors. Nevertheless, changes in the relative abundance of SCFA-producing bacteria are specific to OSA-induced hypertension, which sheds new light on the pathogenesis of the complications. The differences in microbes between OSA and OSA-induced hypertension models are summarised in figure $2 \mathrm{~b}$ and $\mathrm{c}$.

Some similarities exist in the changes of intestinal flora among rodent models of OSA, where these changes are related to hallmarks of OSA, intermittent anoxia and reoxygenation. These similarities hint at potential biomarkers for early diagnosis and treatment of OSA-induced complications. In the studies analysed herein, a decrease in the relative abundance of SCFA-producing bacteria manifested as changes in the gut microbiome in OSA-induced hypertension models. Thus, modulating dietary SCFA intake could influence SCFA-producing bacteria and their metabolic pathways, potentially affecting host metabolism.

\section{Human studies}

\section{Gut microbiome}

Fluctuations in serum microbial metabolites in the gut reflect intestinal floral disorders [25, 28]. The gut contains a dense population of bacteria. The structure of the gut microbiome is relatively stable under normal physiological conditions and appears to be nonpathogenic to the host. OSA changes markers of gut epithelial barrier function and increases intestinal permeability, further disrupting the bacterial environment [58]. In humans, three enterotypes can be distinguished based on the abundance of specific bacteria genera: Bacteroides, Ruminococcus and Prevotella [38]. The enterotype is determined by the species composition, but the principal function is not necessarily determined by the dominant species. Enterotype is not significantly associated with body mass index, age, country of residence or other host characteristics [38]. Sleep is significantly disrupted in OSA patients with an AHI $\geqslant 15$ and a Prevotella enterotype. In addition, obstructive, central and mixed apnoea indices, and mean heart rate are also significantly elevated in AHI $\geqslant 15$ patients with a Prevotella enterotype [59]. Studies have shown that patients with the Prevotella enterotype are susceptible to OSA [59]. The Prevotella enterotype is associated with diets high in carbohydrate (fibre) and simple sugars [60]. Simple carbohydrate consumption promotes inflammation of epithelial cells and obesity, which are strongly associated with OSA [61]. Furthermore, increased abundance of Prevotella is associated with mucosal inflammation, mediated by type 17 T-helper (Th17) cells. Prevotella stimulates antigen-presenting cells to produce Th17-polarising cytokines, mainly by activating Toll-like receptor 2, and can also stimulate epithelial cells to produce inflammatory mediators [62], which may participate in OSA by promoting chronic inflammation. However, another study indicated that a diet rich in fibre can protect the host from OSA by promoting microbial fermentation and SCFA production and that the Prevotella enterotype is related to a much higher risk for OSA [54]. These pathophysiological processes provide new insight into how the enterotype might affect OSA susceptibility. 
Oral microbiome

The human oral cavity contains a diverse community of trillions of microbiota. Streptococcus, Gemella, Abiotrophia, Granulicatella, Rothia, Neisseria and Prevotella are predominant among healthy oral bacteria [63]. Changes in the oral microbiome have been discovered in various systemic diseases, such as T2DM, pancreatic cancer and cardiovascular disease [64-66]. In OSA patients, airway pressure changes dramatically reduce air flow, which affects the moisture and oxygen content in the upper respiratory tract and could explain disorders of the oropharyngeal flora in middle-aged men with moderate-to-severe OSA [67].

Oral bacteria have been confirmed to be involved in the pathogenesis of coronary heart disease and hypertension [68-70]. Haematogenous dissemination of periodontal bacteria is thought to be a cause of cardiovascular disease [71]. Zhong et al. [69] observed Porphyromonas gingivalis in coronary atherosclerotic plaques. However, Ko et al. [72] reported that Porphyromonas genes were not found in blood samples of patients with OSA. In addition, the relative abundance of Porphyromonas is higher in buccal mucosa, and the levels of proinflammatory cytokines are also higher in patients with OSA. These results suggest that oral microorganisms might affect the likelihood of cardiovascular events through inflammatory mediators rather than direct invasion of gum tissue.

\section{Nasal microbiome}

Bacterial communities colonise all areas of the respiratory tract and resist opportunistic pathogens. The nasal microbiome is characterised by Corynebacterium, Propionibacterium and Staphylococcus species [35]. The nasal microbiome profile changes according to illness severity; in patients with severe OSA, enrichment with some commensal organisms (e.g. Streptococcus, Prevotella, Pseudomonas and Haemophilus) is seen compared with nonsevere OSA patients [73].This could be due to recurrent obstruction during sleep causing reflux of oropharyngeal secretions. Surprisingly, the nasal microbiome did not show significant differences in $\alpha$ or $\beta$ diversity after continuous positive airway pressure treatment, which could be explained by the relatively short (3-month) treatment course [37].

\section{Others}

In addition to the upper respiratory tract, the microbiome profile of the lower airway has been studied through bronchoscopy and bronchoalveolar lavage analyses. The levels of Proteobacteria and Fusobacteria were significantly higher, whereas the level of Firmicutes was significantly lower in patients with OSA compared with control patients [74]. A healthy airway microbiota is essential to maintain airway immunity and reduce the risk of infection. Changes in the airway microbiota may contribute to the growth of potential pathogens and airway inflammation in patients with OSA [75]. Studies of the microbiome in patients with OSA and animal models are summarised in table 2.

\section{Summary of microbiome studies}

The microbiota plays a pathophysiological role in OSA and OSA-induced hypertension. Dysbiosis was characterised by a changed Firmicutes to Bacteroidetes ratio in an IH mimicking model [45, 50]. Decreased abundance of SCFA-producing bacteria increased abundance of mucin-degrading bacteria, and increased levels of proinflammatory cytokines appeared to be the major mechanisms underlying cardiac complications of OSA in an OSA-related hypertension model [36, 37, 45, 49, 50]. Overall, however, few studies have investigated the microbiome in OSA patients and animal models and few studies have investigated microbial communities in OSA patients in different parts of the body. Therefore, the consistency in microbiome profiles among OSA patients cannot be easily determined. Importantly, SCFA-producing bacteria and LPSs are involved in obesity and metabolic changes, including in T2DM [76, 77]. Some bacteria, such as Lactobacillus, Bacteroides, Bifidobacterium and Prevotella, which are found in animal models and patients with OSA, have also been implicated in obesity and T2DM [78]. There is large overlap in the disease manifestations and contributing factors for OSA and metabolic disorders, and some microbiome signatures of OSA might be shared with those already observed in obesity and T2DM. Therefore, OSA patients with different complications and different diet or other external factors will have a great impact on intestinal flora, that is to say different OSA phenotypes or combination of comorbidities might be associated with different metabolic and gut microbiota profiles. The unique signatures of OSA awaits further elucidation. There are some other limitations to studies of the microbiome in the context of OSA. First, the sample sizes are generally small, so the results are not reliable. Secondly, few studies have investigated whether intestinal flora changes occur with disease progression; longitudinal metabolomics and multi-omics studies using advanced approaches are therefore needed to increase the number of microbiome biomarkers.

\section{Metabolomics combined with the microbiome}

Only three studies $[25,56,57]$ performed a joint analysis of metabolomics and the microbiome in association with OSA. Xu et al. [25] explored the relationship between the oral microbiome and urine metabolism in 
TABLE 2 Obstructive sleep apnoea (OSA) and the microbiome (rodent and human studies)

\begin{tabular}{|c|c|c|c|c|c|c|}
\hline $\begin{array}{l}\text { First author } \\
\text { [ref.] }\end{array}$ & Model & OSA model & Methods & Biofluid & Relative microbial abundance & Results summary \\
\hline MORENO-INDIAS [36] & $\begin{array}{c}\text { Germ-free } \mathrm{C} 57 \mathrm{BL} / \\
6 \text { male mice }\end{array}$ & 6 weeks IH & $\begin{array}{l}16 \mathrm{~S} \text { rRNA } \\
\text { pyrosequencing }\end{array}$ & $\begin{array}{c}\text { Faecal } \\
\text { samples }\end{array}$ & $\begin{array}{l}\text { IH (Family): } \\
\text { Lachnospiraceae } \uparrow, \\
\text { Prevotellaceae } \uparrow, \\
\text { Peptococcaceae } \downarrow, \\
\text { Erysipelotrichaceae } \downarrow \text {, } \\
\text { Bacteroidaceae } \downarrow \\
\text { IH (Genus): } \\
\text { Paraprevotella } \uparrow, \text { Prevotella } \uparrow, \\
\text { Allobaculum } \downarrow \text {, Turicibacter } \downarrow \text {, } \\
\text { Bacteroides } \downarrow \text {, Odoribacter } \downarrow\end{array}$ & $\begin{array}{l}\text { Under IH, the intestinal } \\
P_{\mathrm{aO}_{2}} \text { fluctuated } \\
\text { intermittently and the } \\
\text { average level decreased } \\
\text { The evenness of the } \\
\text { microbial community } \\
\text { under IH was increased in } \\
\text { the intestine }\end{array}$ \\
\hline MORENO-INDIAS [37] & $\begin{array}{c}\text { Germ-free } \mathrm{C} 57 \mathrm{BL} / \\
6 \text { male mice }\end{array}$ & $\begin{array}{l}6 \text { weeks IH } \\
\text { followed by } \\
6 \text { weeks } \\
\text { normoxic } \\
\text { recovery }\end{array}$ & $\begin{array}{c}16 \mathrm{~S} \text { rRNA } \\
\text { pyrosequencing }\end{array}$ & $\begin{array}{c}\text { Faecal } \\
\text { samples }\end{array}$ & 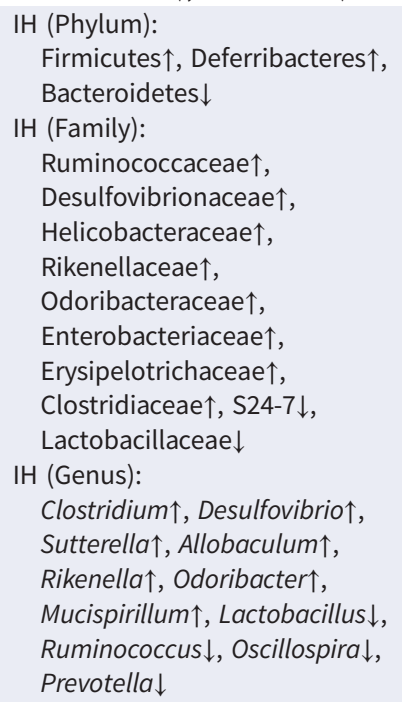 & $\begin{array}{l}\text { Decrease of SCFA-producing } \\
\text { bacteria and increase of } \\
\text { mucin-degrading bacteria } \\
\text { could induce a high level } \\
\text { of LPS in blood in IH } \\
\text { group }\end{array}$ \\
\hline DuRgan [45] & $\begin{array}{l}\text { Rats } \\
\text { HFD }\end{array}$ & $\begin{array}{l}\text { Endotracheal } \\
\text { obstruction } \\
\text { device } \\
\text { implantation }\end{array}$ & $\begin{array}{l}16 \text { S rRNA } \\
\text { sequencing }\end{array}$ & $\begin{array}{c}\text { Faecal } \\
\text { samples }\end{array}$ & $\begin{array}{l}\text { IH+HFD: } \\
\quad \text { Clostridiaceae } \uparrow, \text { Holdemania } \uparrow\end{array}$ & $\begin{array}{l}\text { In the OSA model, the } \\
\text { coexistence of OSA and a } \\
\text { HFD could lead to } \\
\text { hypertension } \\
\text { The ratio of F/B was lower in } \\
\text { normal diet OSA group } \\
\text { than in the HFD alone } \\
\text { group }\end{array}$ \\
\hline GANESH [49] & $\begin{array}{c}\text { Rats } \\
\text { HFD } \\
\text { HFD+Hylon } \\
\text { HFD+Clostridium } \\
\text { butyricum }\end{array}$ & $\begin{array}{l}\text { Endotracheal } \\
\text { obstruction } \\
\text { device } \\
\text { implantation }\end{array}$ & $\begin{array}{l}16 \mathrm{~S} \text { rRNA } \\
\text { sequencing }\end{array}$ & $\begin{array}{c}\text { Faecal } \\
\text { samples }\end{array}$ & $\begin{array}{l}\text { OSA+HFD (Genus): } \\
\text { Lactobacillus } \uparrow \text {, Allobaculum } \uparrow, \\
\text { Bifidobacterium } \uparrow \\
\text { OSA+HFD+C. butyricum (Genus): } \\
\text { Dehalobacterium } \downarrow \\
\quad \text { Anaerostipes } \downarrow\end{array}$ & $\begin{array}{l}\text { C. butyricum and Hylon can } \\
\text { reduce the effects of OSA } \\
\text { on intestinal flora, such as } \\
\text { thinning mucosa and a } \\
\text { decrease of cecum acetate } \\
\text { C. butyricum and Hylon } \\
\text { could alleviate } \\
\text { OSA-induced goblet cell } \\
\text { loss and microglia } \\
\text { activation } \\
\text { Supplementary acetate in } \\
\text { the cecum could prevent } \\
\text { OSA-induced hypertension }\end{array}$ \\
\hline TRIPATHI [56] & $\begin{array}{l}\text { C57BL/6J male } \\
\text { Ldlr }^{-/-} \text {mice } \\
\text { HFD }\end{array}$ & 6 weeks IHH & $\begin{array}{c}16 \mathrm{~S} \text { rRNA } \\
\text { sequencing }\end{array}$ & $\begin{array}{c}\text { Faecal } \\
\text { samples }\end{array}$ & $\begin{array}{l}\text { IHH (Family): } \\
\text { Clostridiaceae } \downarrow \text {, } \\
\text { Coriobacteriaceae } \downarrow \text {, } \\
\text { Lachnospiraceae } \uparrow \\
\text { IHH (Genus): } \\
\text { Oscillospira } \uparrow\end{array}$ & $\begin{array}{l}\text { Under the condition of IHH } \\
\text { and HFD, mice suffered } \\
\text { from intestinal dysbiosis, } \\
\text { which led to changes in } \\
\text { metabolic profiling, mainly } \\
\text { changes in bile acids, } \\
\text { phytoestrogens and fatty } \\
\text { acids }\end{array}$ \\
\hline
\end{tabular}




\section{TABLE 2 Continued}

\begin{tabular}{|c|c|c|c|c|c|c|}
\hline $\begin{array}{l}\text { First author } \\
\text { [ref.] }\end{array}$ & Model & OSA model & Methods & Biofluid & Relative microbial abundance & Results summary \\
\hline LucKING [50] & $\begin{array}{l}\text { 1. Guinea pig } \\
\text { 2. HFD }\end{array}$ & $\mathrm{IH}$ & $\begin{array}{l}16 \text { S rRNA } \\
\text { sequencing }\end{array}$ & $\begin{array}{l}\text { Faecal } \\
\text { samples }\end{array}$ & $\begin{array}{l}\text { IH (Phylum): } \\
\quad \text { Firmicutes } \downarrow \text {, Bacteroidetes } \uparrow\end{array}$ & $\begin{array}{l}\text { In guinea pigs, the } \\
\text { characteristics of } \\
\text { cardiopulmonary disease } \\
\text { (mainly apnoea and } \\
\text { hypertension) in rats } \\
\text { induced by ClH exposure } \\
\text { were not obvious, but it } \\
\text { changed brain stem } \\
\text { neurochemistry, reduced } \\
\text { the richness of intestinal } \\
\text { flora species and changed } \\
\text { the composition of flora }\end{array}$ \\
\hline TRIPATHI [57] & $\begin{array}{c}\text { C57BL/6J male } \\
\text { Ldll }^{-/-} \text {mice } \\
+ \text { HFD } \\
\text { C57BL/6J male } \\
\text { ApoE }^{-1-} \text { mice }\end{array}$ & $\begin{array}{c}6 \text { weeks } \\
\left(\mathrm{Ldll}^{-/-}\right) \text {or } \\
10 \text { weeks } \\
\left(\mathrm{ApoE}^{-/-}\right) \mathrm{IHH}\end{array}$ & $\begin{array}{l}16 \mathrm{~S} \text { rRNA } \\
\text { sequencing }\end{array}$ & $\begin{array}{c}\text { Faecal } \\
\text { samples }\end{array}$ & $\begin{array}{l}\text { IHH (Family): } \\
\text { Clostridiaceae } \downarrow \text {, } \\
\text { Lachnospiraceae } \uparrow\end{array}$ & $\begin{array}{l}\text { Under the intervention of } \\
\text { OSA, atherosclerosis } \\
\text { model involved common } \\
\text { microbial and metabolic } \\
\text { changes }\end{array}$ \\
\hline
\end{tabular}

\begin{tabular}{|c|c|c|c|c|c|c|}
\hline LIU [46] & $\begin{array}{c}\text { Sprague-Dawley } \\
\text { rats } \\
\text { ND } \\
\text { HSD } \\
\mathrm{ClH}+\mathrm{ND} \\
\mathrm{CIH}+\mathrm{HSD}\end{array}$ & 6 weeks IH & $\begin{array}{l}16 \mathrm{~S} \text { rRNA } \\
\text { sequencing }\end{array}$ & $\begin{array}{c}\text { Faecal } \\
\text { samples }\end{array}$ & $\begin{array}{l}\text { IH: } \\
\text { Lactobacillus rhamnosus } \downarrow\end{array}$ & $\begin{array}{l}\text { Because of the synergistic } \\
\text { effect of OSA and HSD, the } \\
\text { abundance of lactobacilli } \\
\text { in intestine decreased } \\
\text { significantly, and the } \\
\text { blood pressure increased } \\
\text { significantly } \\
\text { LGG could prevent the } \\
\text { aggravation of } \\
\text { hypertension by reducing } \\
\text { the level of TMAO, } \\
\text { regulating the imbalance } \\
\text { of Th1/Th2 cytokines, and } \\
\text { inhibiting the } \\
\text { phosphorylation of ERK1/ } \\
\text { 2, Akt and mTOR }\end{array}$ \\
\hline POROYKo [39] & C57BL/6J mice & 4 weeks SF & $\begin{array}{c}16 \mathrm{~S} \text { rRNA } \\
\text { sequencing }\end{array}$ & $\begin{array}{c}\text { Faecal } \\
\text { samples }\end{array}$ & $\begin{array}{l}\text { SF (Phylum): } \\
\text { Firmicutes } \uparrow, \text { Bacteroidetes } \uparrow \\
\text { SF (Families): } \\
\text { Lachnospiraceae } \uparrow, \\
\text { Ruminococcaceae } \uparrow, \\
\text { Lactobacillaceae } \downarrow\end{array}$ & $\begin{array}{l}\text { SF could lead to increased } \\
\text { visceral fat mass and fat } \\
\text { tissue inflammation, as } \\
\text { wells as systemic insulin } \\
\text { resistance and increased } \\
\text { leptin plasma levels } \\
\text { SF had no effect on aerobic } \\
\text { community metabolism, } \\
\text { but suppressed anaerobic } \\
\text { substrate utilisation }\end{array}$ \\
\hline TRIPLETt [40] & $\begin{array}{c}\text { Sprague-Dawley } \\
\text { rats }\end{array}$ & 6 weeks SF & $\begin{array}{l}\text { 16S rRNA } \\
\text { sequence }\end{array}$ & $\begin{array}{c}\text { Intestinal } \\
\text { content }\end{array}$ & $\begin{array}{l}\text { SF ileum (Family): } \\
\text { Enterobacteriaceae } \downarrow \text {, } \\
\text { Lactobacillaceae } \downarrow \text {, } \\
\text { Turicibacteraceae } \uparrow, \\
\text { Clostridiaceae } \uparrow \\
\text { SF caecum (Family): } \\
\text { Ruminococcaceae } \uparrow, \\
\text { Turicibacteraceae } \uparrow \\
\text { SF colon (Family): } \\
\text { Turicibacteraceae, } \\
\text { Clostridiaceae, } \\
\text { Erysipelotrichaceae } \uparrow\end{array}$ & $\begin{array}{l}\text { Chronic SF significantly } \\
\text { increased crypt depth } \\
\text { Chronic SF did not trigger } \\
\text { systemic inflammation in } \\
\text { rats, and microbial } \\
\text { extraintestinal } \\
\text { translocation and invasion } \\
\text { did not occur }\end{array}$ \\
\hline Lu [74] & $\begin{array}{l}11 \text { OSA and } 8 \\
\text { controls (without } \\
\text { medical history } \\
\text { of systemic } \\
\text { disease) }\end{array}$ & $\begin{array}{c}\text { Fibreoptic } \\
\text { bronchoscopy }\end{array}$ & $\begin{array}{c}16 \mathrm{~S} \text { rRNA } \\
\text { sequencing }\end{array}$ & BALF & $\begin{array}{l}\text { OSA (Phylum): } \\
\text { Proteobacteria and } \\
\text { Fusobacteria } \uparrow, \text { Firmicutes } \downarrow\end{array}$ & $\begin{array}{l}\text { The disruption of pulmonary } \\
\text { microbiota in OSA might } \\
\text { be the cause of pulmonary } \\
\text { inflammation and } \\
\text { sensitivity to injury }\end{array}$ \\
\hline
\end{tabular}




\section{TABLE 2 Continued}

\begin{tabular}{|c|c|c|c|c|c|}
\hline $\begin{array}{l}\text { First author } \\
\text { [ref.] }\end{array}$ & Model & OSA model & Methods & Biofluid & Relative microbial abundance \\
\hline $\mathrm{Xu}[25]$ & $\begin{array}{l}30 \text { OSA children } \\
\text { and } 30 \text { controls } \\
\text { (aged 3-11 years } \\
\text { old; without } \\
\text { medical history } \\
\text { of systemic } \\
\text { disease) }\end{array}$ & $\mathrm{AHI}>1$ & $\begin{array}{r}16 \mathrm{~S} \text { rRNA } \\
\text { sequencing } \\
\text { Metabolomics }\end{array}$ & $\begin{array}{l}\text { Buccal } \\
\text { mucosa }\end{array}$ & $\begin{array}{l}\text { OSA (Family): } \\
\text { Veillonellaceae, } \\
\text { Campylobacteraceae, C111 } \\
\text { Paraprevotellaceae } \uparrow \\
\text { (Genus): } \\
\text { Veillonella, Prevotella, } \\
\text { Mogibacterium, } \\
\text { Campylobacter and } \\
\text { Butyrivibrio } \uparrow\end{array}$ \\
\hline Ko [72] & $\begin{array}{l}126 \text { OSA and } 13 \\
\text { controls (without } \\
\text { screening of } \\
\text { complications) }\end{array}$ & $\mathrm{AHI}>5$ & $\begin{array}{c}16 \mathrm{~S} \text { rRNA } \\
\text { pyrosequencing }\end{array}$ & $\begin{array}{l}\text { Buccal } \\
\text { mucosa }\end{array}$ & $\begin{array}{l}\text { OSA (Genus): } \\
\text { Porphyromonas and } \\
\text { Aggregatibacter } \uparrow\end{array}$ \\
\hline
\end{tabular}

Results summary

complications)

\begin{tabular}{|c|c|c|c|c|c|c|}
\hline$Y_{\text {ANG }}[67]$ & $\begin{array}{l}26 \text { male OSA and } \\
25 \text { male controls } \\
\text { (aged } 30- \\
65 \text { years; without } \\
\text { medical history } \\
\text { of systemic } \\
\text { disease) }\end{array}$ & $A H I \geqslant 15$ & $\begin{array}{l}16 \mathrm{~S} \text { rRNA } \\
\text { sequencing }\end{array}$ & Oropharynx & $\begin{array}{l}\text { Glaciecola was not detected in } \\
\text { moderate and severe OSA } \\
\text { groups } \\
\text { Severe OSA: } \\
\text { Tannerella, Anaerovorax and } \\
\text { Halomonas } \downarrow\end{array}$ & $\begin{array}{l}\text { The diversity and abundance } \\
\text { of bacteria in the OSA } \\
\text { group decreased } \\
\text { significantly, and the most } \\
\text { significant diversity decline } \\
\text { occurred in the moderate } \\
\text { OSA group }\end{array}$ \\
\hline Wu [73] & $\begin{array}{l}472 \text { subjects from } \\
\text { the WTCSNORE } \\
\text { and } 93 \text { subjects } \\
\text { from the } \\
\text { Zaragoza sleep } \\
\text { cohort }\end{array}$ & $\mathrm{AHI} \geqslant 5$ & $\begin{array}{c}16 \mathrm{~S} \text { rRNA } \\
\text { sequencing }\end{array}$ & $\begin{array}{l}\text { Nasal } \\
\text { lavages }\end{array}$ & $\begin{array}{l}\text { Severe OSA (Genus): } \\
\text { Streptococcus, Prevotella, } \\
\text { Veillonella and Granulicatella } \uparrow\end{array}$ & $\begin{array}{l}\text { The inflammatory mediators } \\
\text { in nasal lavage fluid of } \\
\text { patients with OSA } \\
\text { increased }\end{array}$ \\
\hline Ko [54] & $\begin{array}{l}93 \text { OSA and } 20 \\
\text { controls (without } \\
\text { screening of } \\
\text { complications) }\end{array}$ & $\mathrm{AHI}>5$ & $\begin{array}{c}16 \mathrm{~S} \text { rRNA } \\
\text { sequencing }\end{array}$ & $\begin{array}{c}\text { Faecal } \\
\text { samples }\end{array}$ & $\begin{array}{l}\text { OSA (Genus): } \\
\text { Faecalibacterium } \downarrow \text {, } \\
\text { Megamonas } \downarrow \text {, } \\
\text { Ruminococcaceae } \downarrow \text {, } \\
\text { Clostridiales } \downarrow \text {, Alistipes } \downarrow \text {, } \\
\text { Bifidobacterium } \uparrow\end{array}$ & $\begin{array}{l}\text { Ruminococcus enterotype } \\
\text { was associated with } \\
\text { increased risk of OSA } \\
\text { The level of Lactobacillus was } \\
\text { related to the level of } \\
\text { homocysteine }\end{array}$ \\
\hline Ko [59] & $\begin{array}{c}52 \text { OSA and } 61 \\
\text { controls (without } \\
\text { medical } \\
\text { history of } \\
\text { gastrointestinal } \\
\text { diseases, } \\
\text { infection, } \\
\text { unexplained } \\
\text { diarrhoea, and } \\
\text { antibiotics or } \\
\text { probiotics used) }\end{array}$ & $\mathrm{AHI} \geqslant 15$ & $\begin{array}{c}16 \mathrm{~S} \text { rRNA } \\
\text { pyrosequencing }\end{array}$ & $\begin{array}{c}\text { Faecal } \\
\text { samples }\end{array}$ & & $\begin{array}{l}\text { The parameters related to } \\
\text { sleep were significantly } \\
\text { damaged in patients with } \\
\text { intestinal type of } \\
\text { Prevotella, whose } \\
\text { obstructive, central and } \\
\text { mixed apnoea index and } \\
\text { mean heart rate were also } \\
\text { significantly increased }\end{array}$ \\
\hline
\end{tabular}

IH: intermittent hypoxia; $P_{\mathrm{aO}}$ : arterial oxygen tension; SCFA: short-chain fatty acids; LPS: lipopolysaccharide; HFD: high fat diet; F/B: Firmicutes/ Bacteroidetes ratio; IHH: IH and hypercapnia; $\mathrm{ClH}$ : chronic intermittent hypoxia; ND: normal diet; HSD: high salt diet; LGG: Lactobacillus rhamnosus GG strain; TMAO: trimethylamine oxide; Th: helper T-cell; SF: sleep fragmentation; BALF: bronchoalveolar lavage fluid; AHI: apnoea-hypopnoea index.

paediatric OSA patients; the overall diversity of oral microorganisms was lower in these patients, but the levels of members of the Veillonellaceae, Campylobacteraceae and C111 Paraprevotellaceae families were higher. Correlations between metabolic changes (in urine samples) and disturbances in the oral microbiome were found, but causal relationships were not explored. Metabolism was also shown to be related to gut dysbiosis in rodent models [56, 57]. These studies described a role for microbial-related metabolic disorders in the initiation of cardiac complications in OSA. However, how microbial disturbances affect metabolic pathways remains to be explored. 
TABLE 3 Summary of current knowledge, limitations and prospects for metabolomics and microbiome studies of obstructive sleep apnoea (OSA)

Summary of findings

Metabolomics

Increased levels of anaerobic metabolites and oxidation products

Disrupted lipid metabolism

\author{
Emergence of dysbiosis in cases of $\mathrm{IH}$ \\ Decrease in the relative abundance of \\ SCFA-producing bacteria in OSA-induced \\ hypertension \\ High susceptibility to OSA in Prevotella \\ enterotype patients \\ Changes in oral, nasal and lung \\ microbiome profiles
}

Limitations

Prospects
Standardised technologies and software as gold standards for future studies

Prospective studies strictly adjusting for confounding variables

To explore functional annotation of unknown metabolites and microbiota in various body fluids or cavities

To focus on microbial and metabolic signatures specific to OSA versus those common to other metabolic diseases

To elucidate casual relationships between metabolomics and the microbiome

More multi-omics studies using advanced approaches

IH: intermittent hypoxia; SCFA: short-chain fatty acid.

Based on the above studies, we assumed that microbiota dysbiosis may participate in the cardiovascular, hepatic, pulmonary and cerebral complications of OSA (figure 2d), but the mechanisms and pathophysiological pathways remain unclear.

\section{Limitations and prospects}

Although there is good awareness and knowledge of OSA, the pathophysiological process is still incompletely understood, which hampers individualised treatment. Our review shows that the limited number of studies on metabolism and the microbiome in the context of OSA are still in the exploratory stage. First, function annotation of unknown metabolites and microbiota in various body fluids and cavities remains to be performed. Secondly, the majority of patient and animal studies are observational, and lack mechanistic experimental data. The short- and long-term dynamics of metabolism and the microbiota remain to be fully explored in the context of OSA. Thirdly, most of the research studies included in this review are focused on animal models of IH or sleep fragmentation, which do not fully reflect the condition of actual OSA patients. Moreover, the dominant genera and relative abundance of gut microflora differ between mice and humans; 85\% of the bacterial genera in mice are not present in humans [79]. Therefore, although mice models seem to be a good method for exploring metabolic and microbial changes, there are many limitations in translating the results to humans, particularly as they pertain to the microbiome. Fourthly, the majority of the changes summarised above are not specific to OSA; they occur in many chronic metabolic diseases characterised by low-grade inflammation. Metabolic and gut microbiota profiles of OSA are affected by complications such as T2DM, nonalcoholic fatty liver disease and cardiovascular comorbidities, including hypertension. Thus, it is difficult to identify a specific gut microbiota dysbiosis signature for OSA. Different OSA phenotypes or combination of comorbidities in OSA might be associated with different metabolic and gut microbiota profiles. Therefore, exploring biomarkers specific to OSA is a worthy target for future studies. In addition, because different gut microbiome sequencing tools and metabolomic methods have been used across studies, interpreting the discrepant microbiome and metabolomic signatures is difficult. Although recent technological improvements have enabled rapid and efficient profiling of the metabolome and microbiome, the use of different platforms and software has resulted in the lack of any gold standard approach to the study of the metabolome and microbiome. Current knowledge, limitations and prospects for metabolomics and microbiome studies of OSA are summarised in table 3.

\section{Conclusions}

Metabolomics can provide a snapshot of the changes in biochemical metabolic pathways associated with OSA, whereas microbiome profiling sheds light on the interactions between an individual and their environment based on the immune response. IH and sleep fragmentation may cause metabolic disorders and microbial dysbiosis. Changes in metabolism are associated with increased anaerobic metabolism and oxidative stress, as well as disrupted lipid metabolism, whereas changes in the gut microbiome are associated with reduced SCFA production and increased expression of LPSs, which leads to local and 
systemic inflammatory responses and metabolic comorbidities. Importantly, it has recently become evident that the metabolomic and microbiota signatures of OSA might be those already observed in metabolic disorders, such as obesity and T2DM [28]. A lack of consideration of the impact of metabolic disorders on "omics" analyses may have complicated the changes in the microbiome and metabolism seen in OSA patients, as well as animal models. Although current research methods are somewhat limited, more multi-omics studies should facilitate the early diagnosis and treatment of OSA.

Provenance: Submitted article, peer reviewed.

Authors' contributions: The authors take responsibility and vouch for the accuracy and completeness of the data and analyses. S. Yin, J. Guan and H. Xu had full access to all of the data in the study and took responsibility for the integrity of the data and the accuracy of the data analysis. Study design: H. Xu, J. Guan and S. Yin. Data collection: H. Xu, J. Guan, H. Yi, S. Wang and X. Zhang. Statistical analysis: H. Xu and X. Zhang. Manuscript draft: $H$. Xu and X. Zhang. All authors have seen and approved the manuscript.

Conflict of interest: None declared.

Support statement: This study was supported by grants-in-aid from Shanghai Municipal Commission of Science and Technology (grant no.18DZ2260200); Innovative research team of high-level local universities in Shanghai; Innovation Program of Shanghai Municipal Education Commission (2017-01-07-00-02-E00047); National Natural Science Foundation of China (82071030, 81970870, 81700896, 81770987, 81701306, 81770988); National Key R\&D Program of China (2017YFC0112500) and a multicentre clinical research project from the School of Medicine, Shanghai Jiao Tong University (DLY201502). Funding information for this article has been deposited with the Crossref Funder Registry.

\section{References}

$1 \quad$ Benjafield AV, Ayas NT, Eastwood PR, et al. Estimation of the global prevalence and burden of obstructive sleep apnoea: a literature-based analysis. Lancet Respir Med 2019; 7: 687-698.

2 McNicholas WT, Bassetti CL, Ferini-Strambi L, et al. Challenges in obstructive sleep apnoea. Lancet Respir Med 2018; 6: 170-172.

3 Ryan S, Cummins EP, Farre R, et al. Understanding the pathophysiological mechanisms of cardiometabolic complications in obstructive sleep apnoea: towards personalised treatment approaches. Eur Respir J 2020; 56: 1902295.

4 Yaffe K, Laffan AM, Harrison SL, et al. Sleep-disordered breathing, hypoxia, and risk of mild cognitive impairment and dementia in older women. JAMA 2011; 306: 613-619.

5 Qian Y, Yi H, Zou J, et al. Independent association between sleep fragmentation and dyslipidemia in patients with obstructive sleep apnea. Sci Rep 2016; 6: 26089.

$6 \mathrm{Xu} \mathrm{H}$, Guan J, Yi H, et al. Elevated low-density lipoprotein cholesterol is independently associated with obstructive sleep apnea: evidence from a large-scale cross-sectional study. Sleep Breath 2016; 20: 627-634.

7 Semelka M, Wilson J, Floyd R. Diagnosis and treatment of obstructive sleep apnea in adults. Am Fam Physician 2016; 94: 355-360.

8 Dunn WB, Broadhurst D, Begley P, et al. Procedures for large-scale metabolic profiling of serum and plasma using gas chromatography and liquid chromatography coupled to mass spectrometry. Nat Protoc 2011; 6: 1060-1083.

9 Newgard CB. Metabolomics and metabolic diseases: where do we stand? Cell Metab 2017; 25: 43-56.

10 Bujak R, Struck-Lewicka W, Markuszewski MJ, et al. Metabolomics for laboratory diagnostics. J Pharm Biomed Anal 2015; 113: 108-120.

11 Barko PC, McMichael MA, Swanson KS, et al. The gastrointestinal microbiome: a review. J Vet Intern Med 2018; 32: 9-25.

12 Conotte S, Tassin A, Conotte R, et al. Metabonomic profiling of chronic intermittent hypoxia in a mouse model. Respir Physiol Neurobiol 2018; 256: 157-173.

13 Ryan S. Adipose tissue inflammation by intermittent hypoxia: mechanistic link between obstructive sleep apnoea and metabolic dysfunction. J Physiol 2017; 595: 2423-2430.

14 Yoon DW, Kwon HN, Jin X, et al. Untargeted metabolomics analysis of rat hippocampus subjected to sleep fragmentation. Brain Res Bull 2019; 153: 74-83.

15 Ząbek A, Stanimirova I, Deja S, et al. Fusion of the H NMR data of serum, urine and exhaled breath condensate in order to discriminate chronic obstructive pulmonary disease and obstructive sleep apnea syndrome. Metabolomics 2015; 11: 1563-1574.

16 Maniscalco M, Motta A. Metabolomics of chronic obstructive pulmonary disease and obstructive sleep apnea syndrome: a comment. Metabolomics 2016; 12: 29.

$17 \mathrm{Xu} \mathrm{H}$, Zheng X, Qian Y, et al. Metabolomics profiling for obstructive sleep apnea and simple snorers. Sci Rep 2016; 6: 30958. 
18 Wang TJ, Larson MG, Vasan RS, et al. Metabolite profiles and the risk of developing diabetes. Nat Med 2011; 17: 448-453.

19 Dong J-Y, Zhang Y-H, Qin L-Q. Obstructive sleep apnea and cardiovascular risk: meta-analysis of prospective cohort studies. Atherosclerosis 2013; 229: 489-495.

20 Zhou M, Guo B, Wang Y, et al. The association between obstructive sleep apnea and carotid intima-media thickness: a systematic review and meta-analysis. Angiology 2017; 68: 575-583.

21 Sorajja D, Gami AS, Somers VK, et al. Independent association between obstructive sleep apnea and subclinical coronary artery disease. Chest 2008; 133: 927-933.

22 Yaggi HK, Concato J, Kernan WN, et al. Obstructive sleep apnea as a risk factor for stroke and death. $N$ Engl J Med 2005; 353: 2034-2041.

23 Bauters F, Rietzschel ER, Hertegonne KBC, et al. The link between obstructive sleep apnea and cardiovascular disease. Curr Atheroscler Rep 2015; 18: 1.

24 Cho K, Yoon DW, Lee M, et al. Urinary metabolomic signatures in obstructive sleep apnea through targeted metabolomic analysis: a pilot study. Metabolomics 2017; 13: 88.

$25 \mathrm{Xu} \mathrm{H}$, Li X, Zheng X, et al. Pediatric obstructive sleep apnea is associated with changes in the oral microbiome and urinary metabolomics profile: a pilot study. J Clin Sleep Med 2018; 14: 1559-1567.

26 Marcus CL, Brooks LJ, Draper KA, et al. Diagnosis and management of childhood obstructive sleep apnea syndrome. Pediatrics 2012; 130: 576-584.

27 Tagaya M, Nakata S, Yasuma F, et al. Relationship between adenoid size and severity of obstructive sleep apnea in preschool children. Int J Pediatr Otorhinolaryngol 2012; 76: 1827-1830.

28 Ferrarini A, Rupérez FJ, Erazo M, et al. Fingerprinting-based metabolomic approach with LC-MS to sleep apnea and hypopnea syndrome: a pilot study. Electrophoresis 2013; 34: 2873-2881.

29 Lebkuchen A, Carvalho VM, Venturini G, et al. Metabolomic and lipidomic profile in men with obstructive sleep apnoea: implications for diagnosis and biomarkers of cardiovascular risk. Sci Rep 2018; 8: 11270.

30 Dall'Acqua S, Stocchero M, Boschiero I, et al. New findings on the in vivo antioxidant activity of Curcuma longa extract by an integrated (1)H NMR and HPLC-MS metabolomic approach. Fitoterapia 2016; 109: 125-131.

31 Aron-Wisnewsky J, Clément K. The gut microbiome, diet, and links to cardiometabolic and chronic disorders. Nat Rev Nephrol 2016; 12: 169-181.

32 Randrianarisoa E, Lehn-Stefan A, Wang X, et al. Relationship of serum trimethylamine N-oxide (TMAO) levels with early atherosclerosis in humans. Sci Rep 2016; 6: 26745.

33 Zhu W, Gregory JC, Org E, et al. Gut microbial metabolite TMAO enhances platelet hyperreactivity and thrombosis risk. Cell 2016; 165: 111-124.

34 Lupachyk S, Watcho P, Stavniichuk R, et al. Endoplasmic reticulum stress plays a key role in the pathogenesis of diabetic peripheral neuropathy. Diabetes 2013; 62: 944-952.

35 Human Microbiome Project Consortium. Structure, function and diversity of the healthy human microbiome. Nature 2012; 486: 207-214.

36 Moreno-Indias I, Torres M, Montserrat JM, et al. Intermittent hypoxia alters gut microbiota diversity in a mouse model of sleep apnoea. Eur Respir J 2015; 45: 1055-1065.

37 Moreno-Indias I, Torres M, Sanchez-Alcoholado L, et al. Normoxic recovery mimicking treatment of sleep apnea does not reverse intermittent hypoxia-induced bacterial dysbiosis and low-grade endotoxemia in mice. Sleep 2016; 39: 1891-1897.

38 Arumugam M, Raes J, Pelletier E, et al. Enterotypes of the human gut microbiome. Nature 2011; 473: 174-180.

39 Poroyko VA, Carreras A, Khalyfa A, et al. Chronic sleep disruption alters gut microbiota, induces systemic and adipose tissue inflammation and insulin resistance in mice. Sci Rep 2016; 6: 35405.

40 Triplett J, Ellis D, Braddock A, et al. Temporal and region-specific effects of sleep fragmentation on gut microbiota and intestinal morphology in Sprague-Dawley rats. Gut Microbes 2020; 11: 706-720.

41 Voigt RM, Forsyth CB, Green SJ, et al. Circadian rhythm and the gut microbiome. In: Cryan JF, Clarke G, eds. International Review of Neurobiology, 131. Cambridge, MA, Academic Press, 2016; pp. 193-205.

42 Nieto FJ, Young TB, Lind BK, et al. Association of sleep-disordered breathing, sleep apnea, and hypertension in a large community-based study. Sleep Heart Health Study. JAMA 2000; 283: 1829-1836.

43 Durán J, Esnaola S, Rubio R, et al. Obstructive sleep apnea-hypopnea and related clinical features in a population-based sample of subjects aged 30 to 70 yr. Am J Respir Crit Care Med 2001; 163: 685-689.

44 Peppard PE, Young T, Palta M, et al. Prospective study of the association between sleep-disordered breathing and hypertension. N Engl J Med 2000; 342: 1378-1384.

45 Durgan DJ, Ganesh BP, Cope JL, et al. Role of the gut microbiome in obstructive sleep apnea-induced hypertension. Hypertension 2016; 67: 469-474.

46 Liu J, Li T, Wu H, et al. Lactobacillus rhamnosus GG strain mitigated the development of obstructive sleep apnea-induced hypertension in a high salt diet via regulating TMAO level and CD4 T cell induced-type I inflammation. Biomed Pharmacother 2019; 112: 108580. 
47 Brooks D, Horner RL, Kozar LF, et al. Obstructive sleep apnea as a cause of systemic hypertension. Evidence from a canine model. J Clin Invest 1997; 99: 106-109.

48 Tan J, McKenzie C, Potamitis M, et al. The role of short-chain fatty acids in health and disease. Adv Immunol 2014; 121: 91-119.

49 Ganesh BP, Nelson JW, Eskew JR, et al. Prebiotics, probiotics, and acetate supplementation prevent hypertension in a model of obstructive sleep apnea. Hypertension 2018; 72: 1141-1150.

50 Lucking EF, O'Connor KM, Strain CR, et al. Chronic intermittent hypoxia disrupts cardiorespiratory homeostasis and gut microbiota composition in adult male guinea pigs. EBioMedicine 2018; 38: 191-205.

51 Samuel BS, Shaito A, Motoike T, et al. Effects of the gut microbiota on host adiposity are modulated by the short-chain fatty-acid binding G protein-coupled receptor, Gpr41. Proc Natl Acad Sci USA 2008; 105: 16767-16772.

52 Canfora EE, Jocken JW, Blaak EE. Short-chain fatty acids in control of body weight and insulin sensitivity. Nat Rev Endocrinol 2015; 11: 577-591.

53 Smith PM, Howitt MR, Panikov N, et al. The microbial metabolites, short-chain fatty acids, regulate colonic $\mathrm{T}_{\text {reg }}$ cell homeostasis. Science 2013; 341: 569-573.

54 Ko CY, Liu QQ, Su HZ, et al. Gut microbiota in obstructive sleep apnea-hypopnea syndrome: disease-related dysbiosis and metabolic comorbidities. Clin Sci (Lond) 2019; 133: 905-917.

55 Pluznick JL, Protzko RJ, Gevorgyan H, et al. Olfactory receptor responding to gut microbiota-derived signals plays a role in renin secretion and blood pressure regulation. Proc Natl Acad Sci USA 2013; 110: 4410-4415.

56 Tripathi A, Melnik AV, Xue J, et al. Intermittent hypoxia and hypercapnia, a hallmark of obstructive sleep apnea, alters the gut microbiome and metabolome. mSystems 2018; 3: e00020-18.

57 Tripathi A, Xu ZZ, Xue J, et al. Intermittent hypoxia and hypercapnia reproducibly change the gut microbiome and metabolome across rodent model systems. mSystems 2019; 4: e00058-19.

58 Barceló A, Esquinas C, Robles J, et al. Gut epithelial barrier markers in patients with obstructive sleep apnea. Sleep Med 2016; 26: 12-15.

59 Ko CY, Fan JM, Hu AK, et al. Disruption of sleep architecture in Prevotella enterotype of patients with obstructive sleep apnea-hypopnea syndrome. Brain Behav 2019; 9: e01287.

60 Conlon MA, Bird AR. The impact of diet and lifestyle on gut microbiota and human health. Nutrients 2014; 7: $17-44$.

61 Orlando A, Cazzaniga E, Giussani M, et al. Hypertension in children: role of obesity, simple carbohydrates, and uric acid. Front Public Health 2018; 6: 129.

62 Larsen JM. The immune response to Prevotella bacteria in chronic inflammatory disease. Immunology 2017; 151: 363-374.

63 Bik EM, Long CD, Armitage GC, et al. Bacterial diversity in the oral cavity of 10 healthy individuals. ISME J 2010; 4: 962-974.

64 Fan X, Alekseyenko AV, Wu J, et al. Human oral microbiome and prospective risk for pancreatic cancer: a population-based nested case-control study. Gut 2018; 67: 120-127.

65 Koren O, Spor A, Felin J, et al. Human oral, gut, and plaque microbiota in patients with atherosclerosis. Proc Natl Acad Sci USA 2011; 108: Suppl. 1, 4592-4598.

66 Long J, Cai Q, Steinwandel M, et al. Association of oral microbiome with type 2 diabetes risk. J Periodont Res 2017; 52: 636-643.

67 Yang W, Shao L, Heizhati M, et al. Oropharyngeal microbiome in obstructive sleep apnea: decreased diversity and abundance. J Clin Sleep Med 2019; 15: 1777-1788.

68 Ueno M, Izumi Y, Kawaguchi Y, et al. Prediagnostic plasma antibody levels to periodontopathic bacteria and risk of coronary heart disease. Int Heart J 2012; 53: 209-214.

69 Zhong LJ, Zhang YM, Liu H, et al. [Detection of periodontal pathogens in coronary atherosclerotic plaques] Zhonghua Kou Qiang Yi Xue Za Zhi 2008; 43: 4-7.

70 Pietropaoli D, Del Pinto R, Ferri C, et al. Definition of hypertension-associated oral pathogens in NHANES. J Periodontol 2019; 90: 866-876.

71 Klarström Engström K, Khalaf $\mathrm{H}$, Kälvegren $\mathrm{H}$, et al. The role of Porphyromonas gingivalis gingipains in platelet activation and innate immune modulation. Mol Oral Microbiol 2015; 30: 62-73.

72 Ko C-Y, Hu A-K, Chou D, et al. Analysis of oral microbiota in patients with obstructive sleep apnea-associated hypertension. Hypertens Res 2019; 42: 1692-1700.

73 Wu BG, Sulaiman I, Wang J, et al. Severe obstructive sleep apnea is associated with alterations in the nasal microbiome and an increase in inflammation. Am J Respir Crit Care Med 2019; 199: 99-109.

74 Lu D, Yao X, Abulimiti A, et al. Profiling of lung microbiota in the patients with obstructive sleep apnea. Medicine (Baltimore) 2018; 97: e11175.

75 Segal LN, Rom WN, Weiden MD. Lung microbiome for clinicians. New discoveries about bugs in healthy and diseased lungs. Ann Am Thorac Soc 2014; 11: 108-116.

76 Cani PD, Amar J, Iglesias MA, et al. Metabolic endotoxemia initiates obesity and insulin resistance. Diabetes 2007; 56: 1761-1772. 
77 Schwiertz A, Taras D, Schäfer K, et al. Microbiota and SCFA in lean and overweight healthy subjects. Obesity (Silver Spring) 2010; 18: 190-195.

78 Aron-Wisnewsky J, Vigliotti C, Witjes J, et al. Gut microbiota and human NAFLD: disentangling microbial signatures from metabolic disorders. Nat Rev Gastroenterol Hepatol 2020; 17: 279-297.

79 Nguyen TL, Vieira-Silva S, Liston A, et al. How informative is the mouse for human gut microbiota research? Dis Model Mech 2015; 8: 1-16. 